Article

\title{
Genomic Features and Molecular Function of a Novel Stress-Tolerant Bacillus halotolerans Strain Isolated from an Extreme Environment
}

\author{
Xiaohui Wu ${ }^{1,2,3,+}$, Huijun Wu ${ }^{1,+}$, Ruoyi Wang ${ }^{1}$, Zhengqi Wang ${ }^{1}$, Yaming Zhang ${ }^{1}$, Qin Gu ${ }^{1}$, Ayaz Farzand ${ }^{1}$, \\ Xue Yang ${ }^{2,3}$, Mikhail Semenov ${ }^{4}$, , Rainer Borriss ${ }^{5,6, *} \mathbb{D}$, Yongli Xie ${ }^{2,3, *}$ and Xuewen Gao ${ }^{1, *}$
}

\section{check for} updates

Citation: $\mathrm{Wu}, \mathrm{X} . ; \mathrm{Wu}, \mathrm{H} . ;$ Wang, R.; Wang, Z.; Zhang, Y.; Gu, Q.; Farzand, A.; Yang, X.; Semenov, M.; Borriss, R.; et al. Genomic Features and Molecular Function of a Novel Stress-Tolerant Bacillus halotolerans Strain Isolated from an Extreme Environment. Biology 2021, 10, 1030. https://doi.org/10.3390/ biology10101030

Academic Editor: Vladimir Kaberdin

Received: 15 August 2021

Accepted: 3 October 2021

Published: 12 October 2021

Publisher's Note: MDPI stays neutral with regard to jurisdictional claims in published maps and institutional affiliations.

Copyright: (c) 2021 by the authors. Licensee MDPI, Basel, Switzerland. This article is an open access article distributed under the terms and conditions of the Creative Commons Attribution (CC BY) license (https:/ / creativecommons.org/licenses/by/ $4.0 /)$.
1 Key Laboratory of Integrated Management of Crop Diseases and Pests, Ministry of Education, Department of Plant Pathology, College of Plant Protection, Nanjing Agricultural University, Nanjing 210095, China; 2019202006@njau.edu.cn (X.W.); hjwu@njau.edu.cn (H.W.); 2019102046@njau.edu.cn (R.W.); 2019102045@njau.edu.cn (Z.W.); 2019802211@njau.edu.cn (Y.Z.); guqin@njau.edu.cn (Q.G.); dr.ayaz21@outlook.com (A.F.)

2 Department of Grassland Science, College of Agricultural and Husbandry, Qinghai University, Xining 810016, China; skryangxue@163.com

3 State Key Laboratory of Plateau Ecology and Agriculture, Qinghai University, Xining 810016, China

4 Department of Soil Biology and Biochemistry, Dokuchaev Soil Science Institute, 119017 Moscow, Russia; mikhail.v.semenov@gmail.com

5 Institut für Biologie, Humboldt Universität Berlin, 10115 Berlin, Germany

6 Nord Reet UG, Marienstr. 27a, 17489 Greifswald, Germany

* Correspondence: rainer.borriss@rz.hu-berlin.de (R.B.); qhdxxyl@163.com (Y.X.); gaoxw@njau.edu.cn (X.G.)

+ The authors Xiaohui Wu and Huijun Wu shared first authorship.

Simple Summary: The Qinghai-Tibet Plateau is known as the "third pole of the world". Due to the extreme geographical location, Qinghai-Tibet Plateau has unique ecosystems characterized by oxygen deficiency, low temperature, high salinity and alkalinity. We carried out the current study to explore the excellent extremophilic Bacillus strains via potential stress resistance as well as biocontrol properties in the Qinghai-Tibet Plateau. We found a Bacillus halotolerans strain with a promising ability to withstand harsh environments and which also exhibits an optimistic biocontrol activity against plant pathogens. We revealed the whole genome sequencing and its taxonomic position and elucidated its molecular functions that were responsible for enhancing stress tolerance as well as suppressing plant pathogens at the genetic level. Lastly, we identified this strain harbored the specific genes associated with stresses resistance, biocontrol function, and can be used as a biological agent in the agriculture field.

Abstract: Due to its topographical position and climatic conditions, the Qinghai-Tibet Plateau possesses abundant microorganism resources. The extremophilic strain KKD1 isolated from Hoh Xil possesses strong stress tolerance, enabling it to propagate under high salinity (13\%) and alkalinity ( $\mathrm{pH}$ 10.0) conditions. In addition, KKD1 exhibits promising biocontrol activity against plant pathogens. To further explore these traits at the genomic level, we performed whole-genome sequencing and analysis. The taxonomic identification according to the average nucleotide identity based on BLAST revealed that KKD1 belongs to Bacillus halotolerans. Genetic screening of KKD1 revealed that its stress resistance mechanism depends on osmotic equilibrium, membrane transportation, and the regulation of ion balance under salt and alkaline stress. The expression of genes involved in these pathways was analyzed using real-time quantitative PCR. The presence of different gene clusters encoding antimicrobial secondary metabolites indicated the various pathways by which KKD1 suppresses phytopathogenic growth. Moreover, the lipopeptides surfactin and fengycin were identified as being significant antifungal components of KKD1. Through comparative genomics analysis, we noticed that KKD1 harbored specific genes involved in stress resistance and biocontrol, thus providing a new perspective on the genomic features of the extremophilic Bacillus species. 
Keywords: Qinghai-Tibet Plateau; Bacillus halotolerans; stress tolerance; biocontrol; genomic features; comparative genomic analysis

\section{Introduction}

The Qinghai-Tibet Plateau (QTP), the largest plateau on earth, with the highest average altitude, is known as the "third pole of the world" [1]. Due to its extreme geographical location and climatic conditions, the QTP has unique extreme ecosystems, characterized by oxygen deficiency, low temperatures, and intense ultraviolet radiation [2]. The rhizosphere of plants growing in the extreme environment could be a rich source of microbes with potential stress resistance and biocontrol properties [3]. Bacillus and Pseudomonas are potential biological control agents [4], and the application of biopesticide is an environmentally friendly alternative to chemical fertilizers [5].

Numerous studies have demonstrated that most biocontrol strains cannot propagate under stressful conditions [6]. A low survival rate is a major challenge for the application of microbial products in extreme environments. The ability to withstand harsh environments is thus critical to microbial survival. Extremophilic strains are continuously confronted with the physicochemical changes associated with extreme environments [3]. We previously isolated numerous Bacillus strains from the QTP. Some of them displayed excellent stress tolerance. The Bacillus sp. RJGP41 and CJCL2 isolated from Tibet have the ability to propagate at $4{ }^{\circ} \mathrm{C}$, while B. safensis GBSW22 and B. zhangzhouensis LLTC93 are able to grow between $10{ }^{\circ} \mathrm{C}$ and $50{ }^{\circ} \mathrm{C}$ [3]. In our previous work, we only reported on the strains that possessed cold and heat stress resistance. Little is known about the tolerance of these strains to salt and alkali stress, including their associated defense mechanisms.

Phytopathogenic fungi severely reduce the yield of agricultural products, and the use of biological fertilizer offers a sustainable way of avoiding this problem [7]. The ability to produce diverse secondary metabolic compounds is the most outstanding biocontrol feature of the Bacillus species. Approximately $10 \%$ of the genes in the genome of the model biocontrol strain $B$. velezensis FZB42 are involved in the production of secondary metabolites, including polyketides, antimicrobial peptides and lipopeptides [8]. Lipopeptides are synthesized by non-ribosomal peptide synthetases (NRPS) that are composed of large multi-enzyme complexes, and which play an important role in inhibiting phytopathogenic pathogens [9]. Preliminary results suggest that stress-tolerant representatives of the genus Bacillus play a major role in QTP ecosystems [6], and their biocontrol capability has been reported by our laboratory. The Bacillus strains isolated from Tibet such as B. halotolerans DGL6 and B. velezensis GBSW11 and DJFZ40 showed strong antagonistic activities towards Phytophthora capsica, Xanthomonas oryzae, and Sclerotinia sclerotiorum [10].

The objective of this study was to isolate stress-tolerant Bacillus spp. from different plant rhizospheres in the QTP and analyze their stress resistance and biocontrol potential at the molecular level. We report here the complete genome of the novel biocontrol strain B. halotolerans KKD1, which was found to be closely related to the mesophilic B. subtilis type strain, but is distinguished by its ability to withstand harsh environmental conditions. Moreover, we revealed its taxonomic position and found that its molecular features were responsible for its capacity to enhance stress tolerance and to suppress plant pathogens. At last, we noticed that KKD1 harbored specific genes associated with stress resistance and biocontrol functions, and that it could be used as a perspective biological agent in agriculture.

\section{Materials and Methods}

\subsection{Collection of Samples and Isolation of Bacteria}

The samples were collected from the rhizosphere of different plants (Brassica napus, Tamarix ramosissima, Nitraria tangutorum, Kobresia pygmaea, Phragmites communis, Peganum harmala, Androsace umbellata, Suaeda glauca) growing in extreme habitats in the QTP (Supplementary 
Table S1). The samples were stored at $4{ }^{\circ} \mathrm{C}$ before further processing. Ten grams of the soil samples was added to $90 \mathrm{~mL}$ of saline solution and incubated with shaking at $200 \mathrm{rpm}$ and $37^{\circ} \mathrm{C}$ for $30 \mathrm{~min}$. After centrifugation, the sediment was diluted $\left(10^{-1}, 10^{-2}\right.$, and $\left.10^{-3}\right)$ and then incubated for $10 \mathrm{~min}$ at $80^{\circ} \mathrm{C}$ to enrich spore-forming bacteria, following which it was streaked onto LB plates at $37^{\circ} \mathrm{C}$ for $12 \mathrm{~h}$. Single colonies were re-streaked several times in order to avoid contaminated clones [3].

\subsection{DNA Isolation and gyrB Gene Sequence Analysis}

Total genomic DNA was extracted from bacterial cells using the DNA Extraction kit D3350-01 (Omega Bio-Tek, Norcross, GA, USA) according to the manufacturer's instructions. The purity and quantity of the extracted DNA were evaluated using the NanoDrop spectrophotometer 1000 (Thermo Fisher Scientific, 81 Wyman Street, Waltham, MA, USA). The $g y r B$ gene sequence was amplified with an appropriate primer pair (Supplementary Table S3). The amplification profile was: $95^{\circ} \mathrm{C}$ for $3 \mathrm{~min}, 32$ cycles of $95^{\circ} \mathrm{C}$ for $15 \mathrm{~s}, 56^{\circ} \mathrm{C}$ for $30 \mathrm{~s}, 72{ }^{\circ} \mathrm{C}$ for $1 \mathrm{~min}$, and the final extension at $72{ }^{\circ} \mathrm{C}$ for $3 \mathrm{~min}$. The gyrB sequences were determined by the Sanger methodology. Bacteria with closely related sequences were identified using the Advanced BLAST search program of NCBI [3]. The neighbor-joining (NJ) tree was constructed from the $g y r B$ sequences using MEGA 7.0 with the p-distance model (https: / / mega.software.informer.com/; accessed on 30 June 2021) [11]. NCBI accession numbers are listed in Supplementary Table S4.

\subsection{Genome Sequencing and Analysis}

Total genomic DNA was obtained as described in Section 2.2. The whole genomes of strains KKD1 (GenBank: CP054584.1, Ref seq: NZ_CP054584.1) and KKLW (GenBank: CP054714.1, Ref seq: NZ_CP054714.1) were sequenced on a PacBio RSII platform (BGI Genomics Co., Ltd.). The genome coverage was 510× (CP054584.1). De novo assembly was performed using Canu v. 1.3 software to obtain the complete circular genome. Automatic gene annotation was performed using the NCBI Prokaryotic Genome Annotation Pipeline (PGAP) [11].

\subsection{Comparative Genome Analysis}

The CRISPR-Cas system, transfer RNA (tRNA) genes, and ribosome RNA (rRNA) genes were predicted by the MinCED (https:/ / github.com/ctSkennerton/minced/tree/ master; accessed on 25 July 2020), tRNAscan-SE (http:/ /lowelab.ucsc.edu/tRNAscan-SE/; accessed on 25 July 2020), and Barrnap (https://github.com/tseemann/barrnap; accessed on 25 July 2020), respectively. Gene islands were analyzed by IslandPath-DIMOB (http: / / pathogenomics.sfu.ca/islandviewer; accessed on 25 July 2020). Gene prediction was carried out by GeneMarks (http://topaz.gatech.edu/GeneMark/; accessed on 25 July 2020), and Prodigal (https:/ / github.com/hyattpd/Prodiga; accessed on 25 July 2020). The annotation of gene functions and metabolic systems was based on the Carbohydrate-Active enZYmes (CAZy) database, (http:/ /www.cazy.org/; accessed on 25 July 2020), Cluster of Orthologous Groups of Proteins (COG, http:/ / www.ncbi.nlm.nih.gov/COG; accessed on 26 August 2020), Kyoto Encyclopedia of Genes and Genomes (KEGG, https: / www. kegg.jp/; accessed on 26 August 2020), Gene Ontology (GO, http://geneontology.org/; accessed on 26 August 2020), Swiss-Prot (http:/ / www.ebi.ac.uk/swissprot/; accessed on 26 August 2020), and Non-Redundant Protein Database (Nr, https: / /www.ncbi.nlm.nih. gov /; accessed on 26 August 2020). Gene clusters involved in the synthesis of secondary metabolites were identified using the online tool antiSMASH 5.0 (https://antismash. secondarymetabolites.org/; accessed on 28 September 2021). Phylogenetic trees were constructed using the neighbor-joining method in MEGA v7.0 software and the iTOL v5 online tool (https://itol.embl.de/; accessed on 15 June 2021). The target genes of the sRNAs were predicted by the online tool TargetRNA2 (http:/ / cs.wellesley.edu/ btjaden/ TargetRNA2/; accessed on 26 August 2020). Mummer software was used for the detection and evolutionary analysis of gene synteny and collinearity. 


\subsection{Inhibition of Phytopathogenic Fungi}

In brief, a paper disk ( $7 \mathrm{~mm}$ in diameter) containing the freshly grown fungal pathogen (Fusarium graminearum) was placed into the center of a Potato Dextrose Agar (PDA) plate. The plates were incubated at $25^{\circ} \mathrm{C}$ for $2 \mathrm{~d}$. Then, $5 \mu \mathrm{L}$ of exponentially growing bacterial cells was inoculated on sterile filter paper discs $(4 \mathrm{~mm})$, which were separately placed in the plates in a cruciform arrangement. The plates were incubated for $3 \mathrm{~d}$ at $25^{\circ} \mathrm{C}$. The diameters of the inhibition zones were recorded, and the percentage of mycelium growth inhibition was calculated by using the following formula: inhibition $(\%)=(\mathrm{C}-\mathrm{T} / \mathrm{C}) \times 100$, where $C$ is the growth in the control and $\mathrm{T}$ is the growth in the treatment. Plates without bacterial inoculated fungal disks were used as controls, and each treatment was performed in triplicate [12].

\subsection{Biocontrol Insights into KKD1 In Vitro Responses to Infection in Wheat}

The biocontrol insights of KKD1 in vitro responses to F. graminearum infection in wheat were also detected. The wheat seeds were surface sterilized, soaked in the bacterial suspension $\left(1 \times 10^{7} \mathrm{cfu} / \mathrm{mL}\right)$, sown in basins, and then cultured in a greenhouse $\left(25^{\circ} \mathrm{C}\right.$, photope$\operatorname{riod} 16 \mathrm{~h} / 8 \mathrm{~h}$ ). Leaves of 7 -day-old wheat plants were inoculated with the F. graminearum mycelium in the middle of the leaf in vitro, following which the wheat leaves were incubated in a sterilized culture incubator at $25^{\circ} \mathrm{C}$ for a week. Sterile water treatments were used as the control, and each experiment was performed with three replicates. The reaction result was monitored by microscopic observation of the treated leaves [13].

\subsection{Extraction of Lipopeptides}

Strain KKD1 was cultured with shaking at $180 \mathrm{rpm}$ for $48 \mathrm{~h}$ at $37^{\circ} \mathrm{C}$ in Landy medium. The culture was then centrifuged at $10,000 \times \mathrm{g}$ at $4^{\circ} \mathrm{C}$ for $10 \mathrm{~min}$ to obtain $100 \mathrm{~mL}$ cell-free supernatants. The supernatant was kept overnight at $4{ }^{\circ} \mathrm{C}$ after adjusting its $\mathrm{pH}$ to 2.0. The precipitates were collected by centrifugation at $10,000 \times \mathrm{g}$ at $4{ }^{\circ} \mathrm{C}$ for $10 \mathrm{~min}$, dissolved in methanol, and the $\mathrm{pH}$ was readjusted to 7.0. The methanolic extracts were passed through a $0.2 \mu \mathrm{m}$ filter [14].

\subsection{MALDI-TOF-MS}

The matrix-assisted laser desorption/ionization time-of-flight mass spectrometry (MALDI-TOF-MS) analysis used the ribosomal protein spectra provided in the proprietary database, and the results were performed in linear positive mode. The molecular masses of the lipopeptide compounds were analyzed by MALDI-TOF-MS with a Bruker Daltonik Reflex MALDI-TOF instrument with a $337 \mathrm{~nm}$ nitrogen laser for desorption and ionization. A-Cyano-4-hydroxycinnamic acid served as the matrix [15].

\subsection{HPLC Analysis}

High-Performance Liquid Chromatography (HPLC) was used for the analysis of the lipopeptides. The lipopeptide mixture was filtered through a $0.2 \mu \mathrm{m}$ membrane filter. A microbore 1200 system (Agilent Technologies, Santa Clara, CA, USA) with an Agilent Eclipse XDB-C18 $5 \mu \mathrm{m}$ column (Macherey-Nagel, Duren, Germany) was used to separate the isoforms with a flow rate of $1 \mathrm{~mL} / \mathrm{min}$ and an injection volume of $20 \mu \mathrm{L}$ [16].

\subsection{Environmental Stress}

Salt stress resistance was examined by inoculating $1 \mathrm{~mL}$ of liquid culture (cultured for $12 \mathrm{~h}$ at $37^{\circ} \mathrm{C}$ ) into $100 \mathrm{~mL} \mathrm{LB}$ broth containing increasing $\mathrm{NaCl}$ concentrations (3-15\%) for 24-96 h. The $\mathrm{OD}_{600}$ of the liquid culture was examined at $12 \mathrm{~h}, 24 \mathrm{~h}, 48 \mathrm{~h}, 72 \mathrm{~h}$, and $96 \mathrm{~h}$. LB broth was used as the control. Each experiment was performed with three replicates [3].

Alkaline stress resistance was examined by inoculating $1 \mathrm{~mL}$ liquid culture (cultured for $12 \mathrm{~h}$ at $37^{\circ} \mathrm{C}$ ) into $100 \mathrm{~mL} \mathrm{LB}$ adjusted to $\mathrm{pH} 7.0-11.0$. The $\mathrm{OD}_{600}$ of the bacterial suspension was examined at different time intervals, including $12,24,48,72$, and $96 \mathrm{~h}$. LB broth was used as the control, and each experiment was performed with three replicates [6]. 


\subsection{Quantitative Real-Time PCR}

The samples were collected at various stress levels to observe the expression of tolerance-related genes. RNA was extracted by the Bacterial RNA extraction kit (OMEGA Bio-tek, Inc. Norcross, GA, USA), cDNA was synthesized by The OneScript ${ }^{\circledR}$ cDNA Synthesis Kit (Applied Biological Materials, Inc. Zhenjiang, China). The primers were designed by the Primer Quest tool of IDT (Supplementary Table S2). The SYBR Green qPCR master mix (TakaraBio, Changping District, Beijing, China) was used for PCR reactions, the expression of genes was studied in a Real-time Thermocycler (QuantStudio-6 Thermo Fisher Scientific, San Jose, CA, USA) by the program of $95^{\circ} \mathrm{C}$ for $30 \mathrm{~s}, 40$ cycles of $95^{\circ} \mathrm{C}$ for $5 \mathrm{~s}$, and $34 \mathrm{~s}$ at $60^{\circ} \mathrm{C}$. The relative expression levels of all samples were calculated and analyzed based on the $2^{-\Delta \Delta C T}$ method [16].

\subsection{Primers, Sequence Alignment, RNA Analysis, and Statistical Analysis}

All the PCR primers relevant to this study were designed by SnapGene v4.1.9. The sequences of the Bacillus species were downloaded from the NCBI database (with a similarity criterion of $>95 \%$ ). The multiple sequence alignment was performed by ClustalW. The concentration and purity of the RNA were determined by measuring the absorbance at 260/280 nm (NanoDrop 1000, Thermo Scientific, Wilmington, DE, USA) and then statistically analyzed by one-way ANOVA and Duncan's test in SPSS Statistics version v17.0 (SPSS Inc., Chicago, IL, USA) and Excel 2019 (Microsoft Corp., Redmond, WA, USA). Significance was assessed at $p \leq 0.05$. The graphs were edited by GraphPad Prism 8.0.1, Adobe Photoshop 2021, and Adobe Illustrator 2021.

\section{Results and Discussion}

\subsection{Isolation and Identification of the Stress-Tolerant Bacillus spp. from the QTP}

Utilizing microbes from the QTP as biopesticide is a reasonable approach for the development of an environmentally friendly biological control approach to sustainable agriculture under harsh environmental conditions [3]. A total of 25 strains were isolated from the rhizospheric soil sampled in different extreme habitats (deserts, saline-alkali soil, and farmlands) of the QTP (Supplementary Table S1). The average altitude of these sampling sites was $3025 \mathrm{~m}$. While 16S rRNA sequences are not sufficient to distinguish between closely related species of the $B$. subtilis species complex, gyrB sequences yield sufficient resolution of closely related species. Therefore, the partial gyrB sequences (Supplementary Table S3) were used for the taxonomic identification. In the phylogenetic tree (Figure 1), the strains clustered into four different species: Bacillus atrophaeus (19 strains), Bacillus velezensis (two strains), Bacillus thuringiensis (two strains), Bacillus subtilis (one strain) and Bacillus halotolerans (one strain). The number of B. atrophaeus strains selected from the extreme environment of the QTP was remarkable. Due to its promising stress resistance, $B$. halotolerans KKD1 was selected for further analysis. KKD1 was isolated from the rhizosphere of Androsace mbellate in Hoh Xil Natural Nature reserve $\left(34^{\circ} 19^{\prime} \mathrm{N}\right.$ and $89^{\circ} 25^{\prime} \mathrm{E}, 4680 \mathrm{~m}$ above sea level), which is located in the northeastern part of the QTP. The sampling site is characterized by alkaline soil, high salinity, a low annual temperature $\left(-4^{\circ}\right.$ to $\left.-9{ }^{\circ} \mathrm{C}\right)$, and high $\mathrm{UV}$ radiation.

\subsection{The Genome of B. halotolerans KKD1}

To further explore the genes features of KKD1, we assessed the whole-genome analysis. Genome sequencing and mining supported the phenotypic features observed in B. halotolerans KKD1 at the molecular level. Whole-genome sequence analysis of $B$. halotolerans KKD1 was accomplished using the Illumina sequencing platform (see Methods). The KKD1 genome (Figure 2) consisted of a 4,248,134-bp circular chromosome with an average GC content of $43.57 \%$. KKD1 encoded 4465 predicted protein-coding sequences (CDSs), 85 tRNA genes, 30 rRNAs, and 28 tandem repeat sequences. In total, the 3307 CDS sequences comprised 25 functional COGs (Supplementary Figure S1), 42 GO categories (Supplementary Figure S2), and 30 KEGG metabolic pathways (Supplementary Figure S3). Twenty-one 
sRNAs were identified, eight of which were related to stress-resistance and biocontrol traits, and their target mRNA binding sites are described in Supplementary Figure S4. In total, 441 genes in B. halotolerans KKD1 clustered into nine different DNA islands and were probably acquired via horizontal gene transfer. Some of these gene products exhibited striking similarity to sodium: proton antiporter and UV damage repair protein on the amino acid sequence level. In addition, $B$. halotolerans KKD1 harbored six different confirmed CRISPR-Cas systems, which were defined as acting against invading genetic elements.

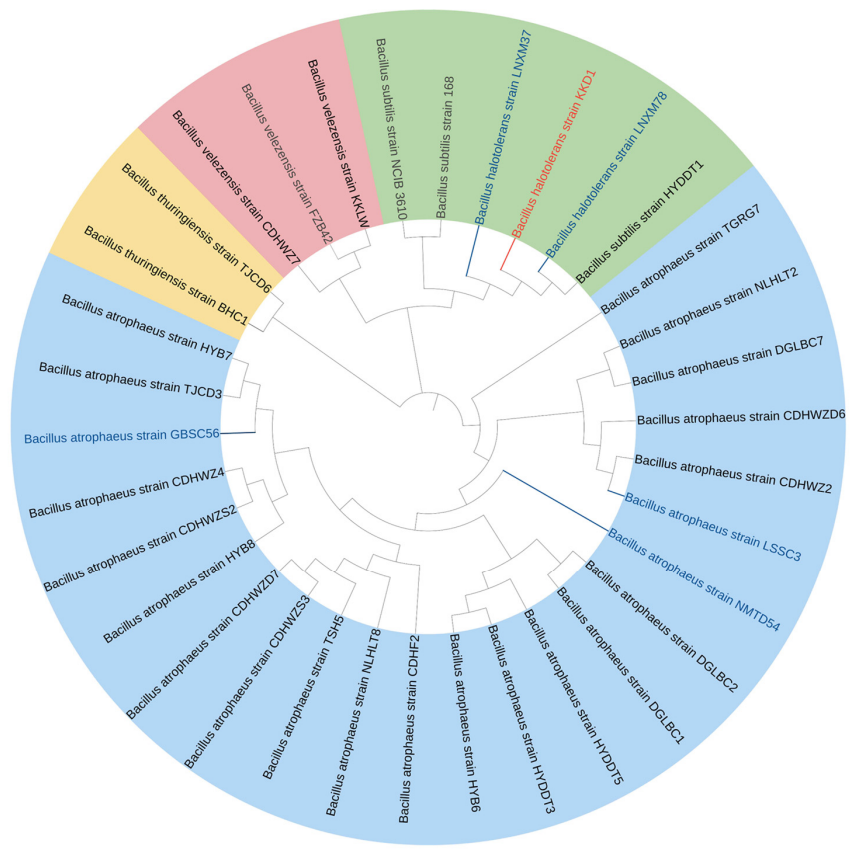

Figure 1. Phylogenetic tree based on the alignment of partial gyrB nucleotide sequences. The strains were clustered into four different groups: B. atrophaeus, B. velezensis, B. halotolerans, and B. thuringiensis. B. halotolerans KKD1 is labelled by red letters, and the model strains are labelled by grey letters. Strains previously isolated from the Qinghai-Tibetan Plateau are labelled by blue letters [3].

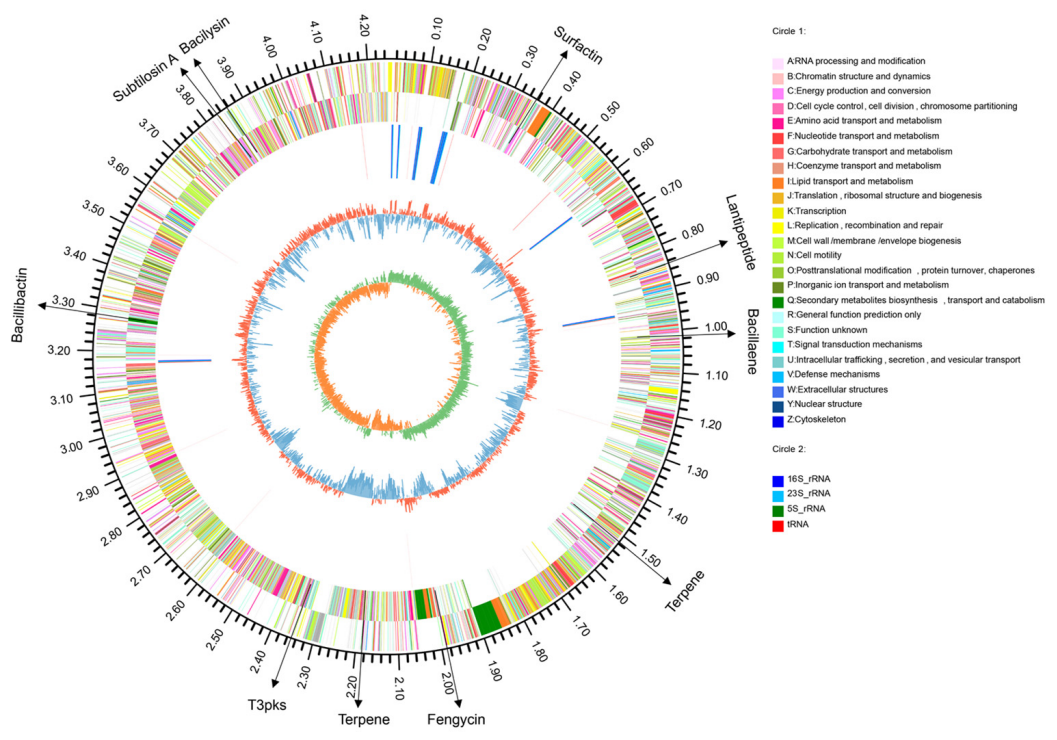

Figure 2. The whole-genome map of $B$. halotolerans KKD1. The genome map consists of seven different circles. From the inner circle to the outer circle: (1) GC skew. (2) G + C content. (3) The locations of the secondary metabolite clusters. (4) Reverse COG function classification. (5) Forward COG function classification. (6) Reverse CDS. (7) Forward CDS. 
Comparison of B. halotolerans KKD1 with the model strains B. velezensis FZB42 and B. subtilis 168 revealed that the three genomes had 3122 core genes in common, but 588 genes were unique to $B$. halotolerans KKD1 (Figure 3A). Structural genome analysis with the Mummer software revealed that B. halotolerans KKD1 and B. subtilis 168 share a conserved genomic structure and homologous gene composition, but some inversion events also occurred in the genome of these two strains during evolution (Figure 3B-D). On the contrary, B. halotolerans KKD1 and B. velezensis FZB42 showed a less conserved genomic structure and homologous gene composition (Figure 3E,F).
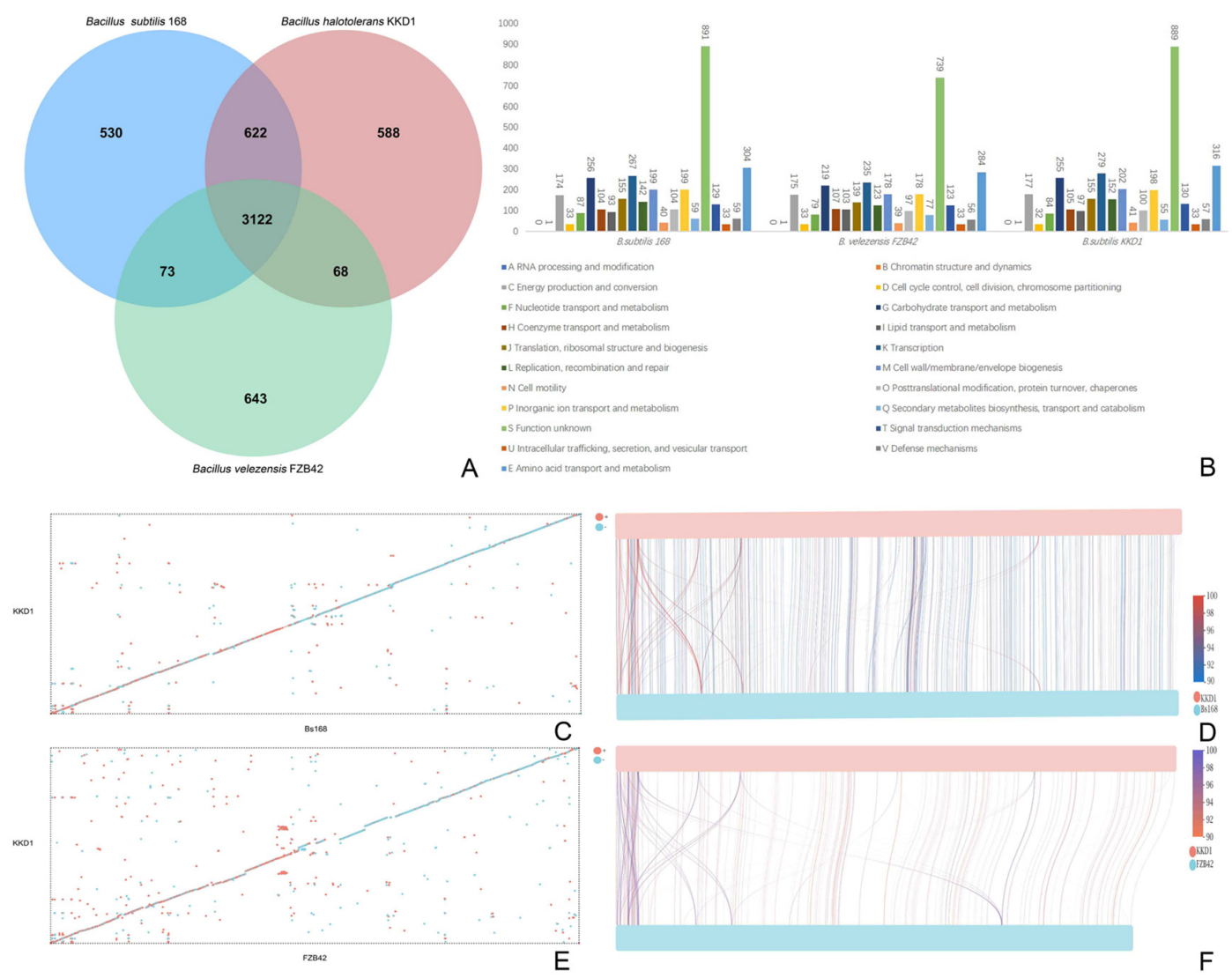

Figure 3. Comparative genomic analysis of KKD1 with model Bacillus strains. (A) Each strain is represented by an oval. The number of orthologous genes shared by all strains (B. halotolerans KKD1, B. velezensis FZB42 and B. subtilis 168) is in the center. Numbers in nonoverlapping portions of each oval show the number of CDSs unique to each strain. (B) Genome analysis of the three strains based on the COG database. (C) A dot plot of the collinearity analysis between $B$. halotolerans KKD1 and B. subtilis 168 . The abscissa represents B. subtilis 168 , and the ordinate represents B. halotolerans KKD1. (D) The line graph of collinearity analysis between B. halotolerans KKD1 and B. subtilis 168. (E) A dot plot of collinearity analysis between B. halotolerans KKD1 and B. velezensis FZB42. The abscissa represents B. velezensis FZB42, and the ordinate represents B. halotolerans KKD1. (F) The line graph of collinearity analysis between B. halotolerans KKD1 and B. velezensis FZB42. Note: The blue dots in $(\mathbf{C}, \mathbf{E})$ represent the forward comparison of two strains, the composition and direction of the sequences are the same, and the red dots represent the reverse comparison of two samples. The sequence composition is the same, and the direction is opposite. Different colors in $(\mathbf{D}, \mathbf{F})$ indicate different regions in the samples, and the color and width of the color band indicate the alignment length and the region homology.

\subsection{Taxonomical Assignment of Bacillus halotolerans KKD1 by Its Core Genome}

The core genome of KKD1 was used for phylogenomic analysis, applying the EDGAR software package [17]. According to the phylogenetic tree based on the whole genomes of the $B$. subtilis species complex, $B$. halotolerans KKD1 is a member of the $B$. subtilis species complex sensu stricto, as shown in the upper part of Figure 4 . Two clusters formed by the B. subtilis / B. vallismortis / B. tequilensis group and by B. mojavensis / B. halotolerans appear 
to be closely related. By contrast, $B$. velezensis KKLW is a member of the more distantly related operational B. amyloliquefaciens group consisting of B. amyloliquefaciens, B. siamensis, and B. velezensis [18]. It should be noted that B. subtilis, B. licheniformis, and B. pumilus were originally defined as being the first members of the B. subtilis species complex [19]. Due to the high-resolution data offered by modern phylogenomic trees based on whole genomes, today the $B$. subtilis species complex contains numerous members, and these three species appear to be very remote from each other.

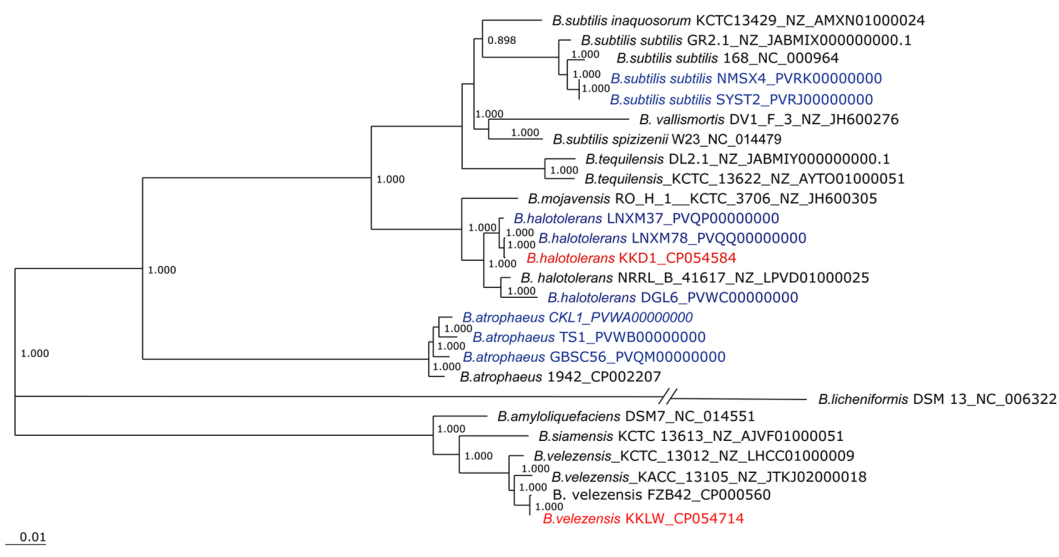

Figure 4. Phylogenetic tree. Phylogenetic tree for 26 genomes constructed from a core of 1743 genes per genome (45,318 in total). The core has 519,198 AA-residues/bp per genome and 13,499,148 in total. B. halotolerans KKD1 is labelled by red letters. Strains previously isolated from the Qinghai-Tibetan plateau are labelled by blue letters. B. licheniformis DSM13 was used as an outgroup. FastTree software was implemented with the EDGAR package to generate an approximately-maximum-likelihood phylogenetic tree. The values at the branches of the FastTree trees are not bootstrapped values but are local support values computed by FastTree using the Shimodaira-Hasegawa test (FastTree, http:/ / www.microbesonline.org/fasttree/; accessed on 4 October 2021).

In order to analyze the taxonomical relationships of KKD1 more precisely, the average nucleotide identity based on BLAST (ANIb) was applied. According to the recommended species cut-off, defined as being 96\% [19], KKD1 was found to be a representative of $B$. halotolerans, while KKLW belongs to the species B. velezensis (Figure 5). This is consistent with our results obtained by gyrB sequence analysis described in Section 3.1.

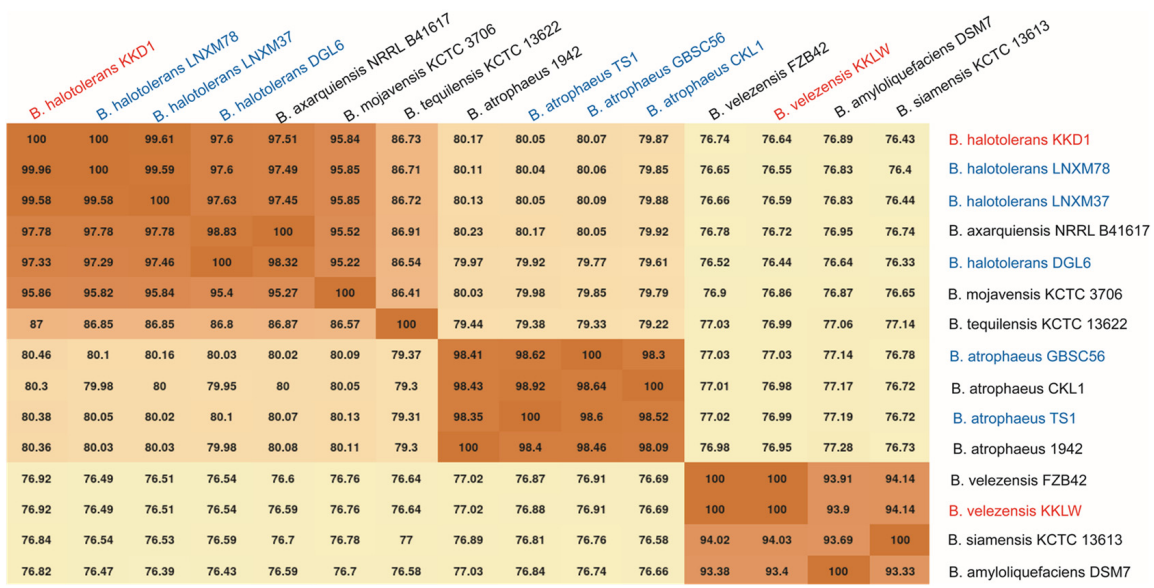

Figure 5. Heatmap of the ANIb matrix calculated for the genomes of B. halotolerans KKD1. Heatmap of the ANIb matrix calculated for the genomes of B. halotolerans KKD1 and closely related species. The method was based on a BLASTN comparison of the genome sequences as described by Goris et al. [20]. B. halotolerans KKD1 is labelled in red letters. Strains isolated from the QinghaiTibetan plateau are labelled in blue letters. 


\subsection{B. halotolerans KKD1 Tolerates Different Environmental Stress Conditions}

The $B$. halotolerans strain KKD1 grew well at $13 \%$ salinity, while the model strains B. velezensis FZB42 and B. subtilis 168 were unable to grow under that condition (Figure $6 \mathrm{C}$ ). Moreover, The $B$. halotolerans strain KKD1 grew well under alkaline conditions ( $\mathrm{pH} 10.0)$, while B. subtilis 168 only grew only weakly, and B. velezensis FZB42 did not grow (Figure 6F). This is in contrast to the taxonomically related model strains B. velezensis FZB42 [8] and B. subtilis 168 [21], which also belong to the B. subtilis species complex [19].
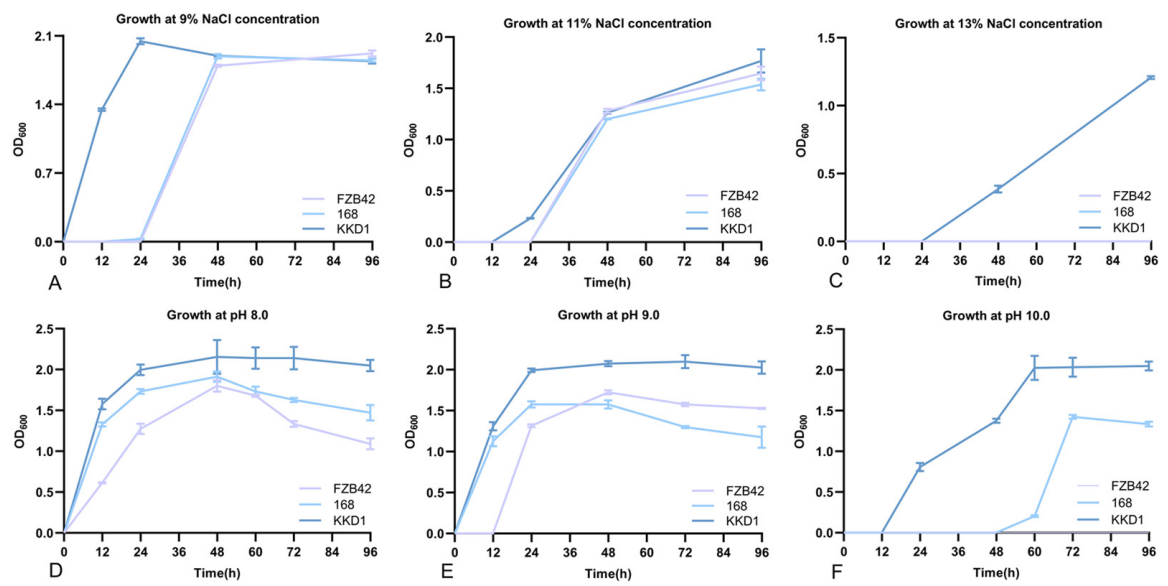

Figure 6. Growth curve of $B$. halotolerans KKD1 under different stress conditions. Growth curve under salt stress $(9 \%, 11 \%, 13 \%)$ and growth curve under alkaline stress ( $\mathrm{pH} 8.0, \mathrm{pH} 9.0, \mathrm{pH} 10.0)$. The error bars represent the mean standard deviation of each treatment repeated three times with three replicates $(\mathbf{A}-\mathbf{F})$.

\subsection{Genome Mining for Genes Possibly Involved in Tolerance to Stress Conditions} 3.5.1. Signal Transduction Pathways Involved in Salt Tolerance

We speculate that its extreme habitat might endow B. halotolerans KKD1 with stronger self-selectivity at the genetic level. Through genome mining, we found that $B$. halotolerans KKD1 harbored multiple pathways for tolerating complex and diverse stress conditions. To further understand the salt stress resistance mechanism of KKD1 at the molecular level, the genomic features were screened using the GO, COG, and KEGG databases, and key genes involved in these different pathways were compared. The expression of genes involved in these pathways was analyzed using RT-qPCR (Figure 7A).
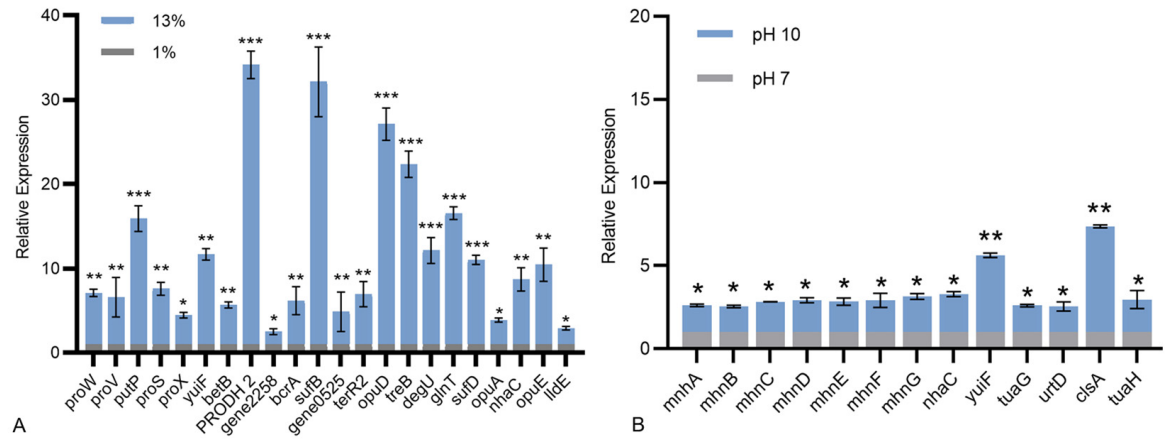

Figure 7. Relative expression levels of different genes involved in stress resistance. (A) The relative expression levels of different genes in B. halotolerans KKD1 grown at $1 \%$ and $13 \%$ salinity. (B) The relative expression levels of different genes in B. halotolerans KKD1 grown at pH 7.0 and pH 10.0. Data are the average thickness \pm the standard deviation (SD) of three independent experiments. ${ }^{*}$, indicates a significant difference $(p<0.05),{ }^{* *}$, indicates an extremely significant difference $(p<0.05)$, $* * *$, indicates an extremely significant difference $(p<0.01)$ compared to that of control group. 
The presence of genes related to sodium transporters suggested that one strategy by which KKD1 endures high salinity is by maintaining cellular homeostasis by transporting sodium. Gene0757 probably encodes sodium/proline symporter, it is the homologue of $o p u E$ in B. subtilis and will be called opuE. The expression of opuE and $p u t P$ was upregulated 15.91- and 10.46-fold, respectively. The sodium/proline symporters opuE and putP are members of the solute/sodium symporter (SSS) family. They are essential membrane integrated proteins that couple the flow of $\mathrm{Na}^{+}$ions driven by electrochemical $\mathrm{Na}^{+}$gradients to the transport of proline across biological membranes [22]. Gene2041 probably encodes sodium: proton antiporter, it is the homologue of $n$ haC in B. mycoides and will be called nhaC. The expression of $y u i F, n h a C$, gene0525 and gene2258 was upregulated 11.68-, 8.71-, 4.88- and 2.52-fold, respectively. These four genes are sodium: proton antiporters and sodium: glutamate symporters, which are responsible for maintaining cellular homeostasis by exchanging protons for sodium ion.

The presence of genes involved in various biosynthesis activities suggested that another strategy by which KKD1 endures high salinity is by accumulating compatible solutes. Proline, betaine, and trehalose are the main compounds maintaining osmotic balance in cells [23]. Glycine betaine is one of the most important osmotic-regulating chemicals and it can accumulate rapidly in cells to maintain osmotic balance and protect pivotal enzymes under salt stress. The genes involved in glycine/betaine metabolism, namely, proV, proW, proX, opuA and opuD were highly expressed (3.89- to 27.12-fold); they are all glycine/betaine $\mathrm{ABC}$ transporters. The glycine/betaine $\mathrm{ABC}$ transporters are dimerized by binding to ATP and transferring the substrate to the other side of the membrane by changing their conformation [24]. Based on the K00130 and the K00128 pathways in KEGG, betB was annotated as betaine-aldehyde dehydrogenases, which can activate glycine, serine, and threonine metabolism; it upregulated 5.89-fold when KKD1 was exposed to 13\% salinity. Trehalose is a nonreducing disaccharide synthesized by trehalose synthase, which protects cells and bioactive substances [25]. The expression of trehalose permease IIC protein TreB and trehalose operon TreR2 regulator was also enhanced (6.95- to 22.36-fold). Proline is a compatible osmotic regulator, we found that the expression of these genes involved in the proline pathway, namely proS and gene0381 (PRODH 2) was highly upregulated (7.60- to 34.15-fold). Gene0381 encodes proline dehydrogenase, it is the homologue of PRODH 2 in B. marisflavi, and will be called PRODH 2. Proline dehydrogenase (PRODH) also known as proline oxidase (POX), the first step in the two-step oxidation of proline in bacteria. It plays the biological role in cell homeostasis and adapts through energetic, physiological and adaptive processes in eukaryotes [26]. Additionally, the proline-tRNA ligase ProRS and the proline dehydrogenase act together to decrease intracellular salt stress pressure [22].

Based on this result, we speculated that the histidine signal transduction pathways act as the sensory network and the two-component systems act as basic stimulus-response coupling mechanisms to sense environmental stress [6]. KKD1 might eliminate $\mathrm{Na}^{+}$and absorb various solute to keep the intracellular $\mathrm{NaCl}$ concentration lower than the external environment and thus survive under high salt conditions [27]. Further research is necessary to elucidate their action mechanism in B. halotolerans KKD1 in more detail.

\subsubsection{Alkaline Resistance}

Based on the results obtained by the KEGG functional annotation of $B$. halotolerans KKD1, we hypothesized that the bacterium response to alkaline pressure was mainly due to export, catabolism, environmental adaptation, and signal molecular interaction.

Resistance and $\mathrm{pH}$ homeostasis proteins (MnhA-G) were found in the K05565 signaling pathway. The expression of these genes was upregulated (2.54- to 3.14-fold) under alkaline stress (Figure 7B). They maintain the normal growth of cells by regulating intracellular osmosis. On the test results, the expression of yuiF was upregulated significantly 5.62-fold. The yuiF is a $\mathrm{Na}^{+} / \mathrm{H}^{+}$antiporter, which is involved in the $\mathrm{K} 03315$ and $\mathrm{K} 07084$ signaling pathways in KEGG. The $\mathrm{Na}^{+} / \mathrm{H}^{+}$antiport activity is primarily aimed at extruding $\mathrm{Na}^{+}$to the external space, and the $\mathrm{Na}^{+} / \mathrm{H}^{+}$antiporter YuiF imports extracellular $\mathrm{H}^{+}$to 
exchange intracellular $\mathrm{Na}^{+}$, thus acidifying the cytoplasm [28]. We also found that $u r t D$ upregulated 2.56-fold in B. halotolerans KKD1 under alkaline stress. It is reported that the ATP-binding cassette $(\mathrm{ABC})$ transporter urtD maintains normal homeostasis by transporting amino acids and ions [29]. $\mathrm{Na}^{+} / \mathrm{H}^{+}$antiporters and $\mathrm{ABC}$ transporters showed the same response when $B$. halotolerans KKD1 is under salt and alkaline stress [30]. The expression of tua $G$ and tuaH was upregulated 2.61- and 2.97-fold, respectively. The glycosyl transferase TuaG and the teichuronic acid biosynthesis glycosyl transferase TuaH are required for polymerizing teichuronic acid. The production of teichuronic acid enables cells to repel $\mathrm{OH}^{-}$and adsorb more $\mathrm{Na}^{+}$and $\mathrm{H}^{+}$[31]. All of these genes maintained the intracellular $\mathrm{pH}$ at a lower level than the extracellular $\mathrm{pH}$ by concentrating the dissolved substances in the cytoplasm.

In addition, through the comparative genomics analysis, we noticed that KKD1 harbors specific genes involved in stress resistance, thus providing a new perspective on the genomic features of extremophilic Bacillus species. B. halotolerans KKD1 contains four genes related to proton transportation, cytoplasm acidification, and signal transduction. Gene2977 probably encodes the sodium ABC transporter ATP-binding protein; it is the homologue of $b c r A$ in $B$. subtilis, and we renamed it as the $b c r A$. The solute: sodium symporter family transporter (gene2258), and sodium: dicarboxylate symporter (gene0525) and the two-component sensor histidine kinase VanS, do not occur in the model strains FZB42 and 168. We speculate that these proteins are involved in sensing and response of environmental signals, such as the transport of extracellular $\mathrm{H}^{+}$to exchange intracellular $\mathrm{Na}^{+}$, and the acidification of the cytoplasm, so further regulating the balance of osmotic pressure inside and outside of the cell. The function of these genes requires further experimental verification and we expect to find novel genetic features that elucidate the mechanisms of stress resistance occurring in the extremophilic representatives of the genus Bacilllus.

\subsection{Biocontrol of Plant Pathogens In Vitro}

In order to investigate the biocontrol potential of KKD1 in vitro, we proved its antifungal activity by choosing Fusarium graminearum [12]. The fungal pathogen F. graminearum has a broad host range, causing scab in major cereal crops, such as wheat, barley, and maize, and is responsible for substantial economic losses every year. A strong suppressive effect was detected on agar plates containing F. graminearum when it was co-cultured with KKD1. The average size of the inhibition zone was $\geq 11 \mathrm{~mm}$ (Figure 8B). In addition, the lipopeptide extracts of KKD1 were also efficient in inhibiting F. graminearum (Figure 8C). Subsequently, B. halotolerans KKD1 was assessed for its ability to reduce the lesion diameter of wheat leaves. Compared with the control, the growth of the lesion diameter was very slow on the wheat leaves sprayed with a bacterial suspension of KKD1. The biocontrol effect of KKD1 visibly inhibits F. graminearum infection in wheat. Our results demonstrated that $B$. halotolerans KKD1 was able to partially overcome the pathogenic effects and had the potential to inhibit the development of plant disease (Figure 8A).

\subsection{Genome Mining for Gene Clusters Devoted to the Synthesis of Antimicrobial Secondary Metabolites}

Our genome mining results revealed that KKD1 possesses numerous genes involved in the production of bioactive compounds [32]. AntiSMASH version 6.0 [33] was used to predict the gene clusters in B. halotolerans KKD1 possibly involved in the control of plant disease (Figure 8). In total, KKD1 harbors 10 different secondary metabolite gene clusters, three of which were not detected in the model strains FZB42 and 168. Six of the biosynthetic gene clusters (BGCs) in KKD1 are listed in the MIBiG data bank [34] and are common in the representatives of the $B$. subtilis species complex. Producing compounds encoded by these gene clusters is considered the main route by which $B$. halotolerans KKD1 controls plant disease [35]. 


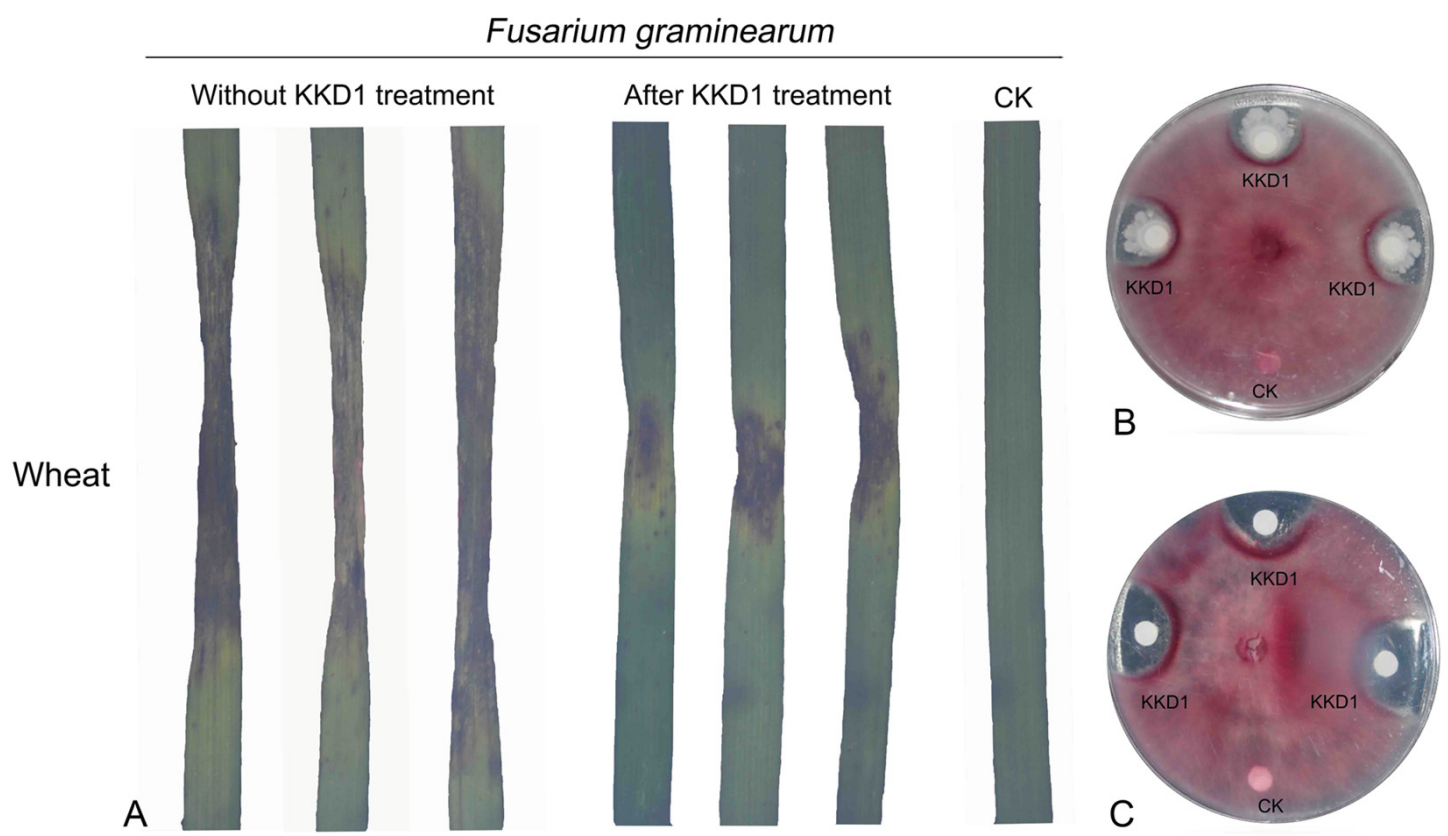

Figure 8. Antagonistic action of B. halotolerans KKD1 versus F. graminearum. (A) In vitro response of wheat leaves after infection with $F$. graminearum. Representative lesion lengths in wheat leaves following inoculation with control F. graminearum and F. graminearum after cultivation with strain KKD1. (B) Inhibition zones of F. graminearum caused by the KKD1 colonies. (C) Inhibition zones of F. graminearum caused by the lipopeptide extracts of KKD1.

We assume that the antifungal activity of KKD1 relies mainly upon the non-ribosomalsynthesized lipopeptides fengycin and surfactin. Both are cyclopeptides linked to a ß-fatty acid chain [36]. The lipopeptides surfactin, fengycin/plipastatin, and bacillibactin are synthesized non-ribosomally and have been previously detected in B. subtilis [37]. Surfactin is a lipoheptapeptide with antimicrobial, antiviral, and anti-mycoplasma activity. The $25 \mathrm{~kb}$ srf operon in B. halotolerans KKD1 was similarly organized as in B. subtilis 168. Fengycin is a cyclic lipodecapeptide with antifungal action. Surfactin contributes to inducing systemic resistance against plant pathogens [38], and fengycin can act directly against pathogenic fungi by destabilizing their membrane integrity, although its role in stimulating the ISR response in plants cannot be excluded [8].

The siderophore bacillibactin can absorb and accumulate Fe ions under iron limitation and has an important competitive role with other microorganisms [12]. Functional $d h b$ and ent gene clusters involved in the synthesis of bacillibactin were also detected in B. halotolerans KKD1. The dipeptide bacilysin (1-alanine-[2,3-epoxycyclohexano-4]-1alanine) is efficient in the suppression of plant pathogenic bacteria. Bacilysin was encoded by the bacABCDEFG gene cluster in B. halotolerans KKD1.

Polyketide synthases (PKSs) are involved in the non-ribosomal synthesis of polyketide antibiotics [8]. The pks gene cluster present in B. halotolerans KKD1 encoded bacillaene, an open-chain enamine acid with extended polyene structure that is known for its antagonistic effect against bacteria [39]. In contrast to the lipopeptides and polyketides described above, lanthipeptides are ribosomally synthesized and post-translationally modified peptides containing lanthionine or labionin structures [40]. The sactipeptide subtilosin A, an example of an unusual lantibiotic, has a macrocyclic structure with three thioether bonds. The gene cluster for subtilosin A synthesis was detected in the genome of KKD1, and we also detected that peptidase M16 was part of the subtilosin A biosynthetic gene cluster in KKD1. It inhibits Gram-positive bacteria and is expressed under stress conditions [3]. In addition, KKD1 harbored three gene clusters, whose products have not yet been identified. One biosynthesis gene cluster in the genome of $B$. halotolerans KKD1 contains a protein kinase/lanthionine synthetase C (LanC) family protein. Class III lanthipeptides with a 
molecular weight of $1738 \mathrm{Da}$ are encoded by five gene copies located downstream from the lan C gene. Type III polyketide synthase (T3PKS) is also common in a multitude of Bacillus species and might contribute to its antagonistic activity [3]. A chalcone and stilbene synthase protein is encoded in the KKD1 genome. Terpene occurs in nature with varied structural compounds and has been reported to possess antimicrobial activity [8]. The products of two terpene biosynthesis gene clusters presented in B. halotolerans KKD1 may contribute to its bacteriostatic and bactericidal effects [41].

The gene clusters involved in synthesis of secondary metabolites of strain $B$. halotolerans KKD1 and model strain $B$. velezensis FZB42 were compared, and huge differences were found. For comparison, we have also included the results of our comparative analysis performed with B. velezensis KKLW, which isolated from the same harsh environment (QTP) as KKD1. According to the corresponding NCBI genome neighbor report, the genome sequence of KKLW (CP054714.1) was found to be nearly identical to the model strain FZB42 (CP000560.2). During our analysis, the gene clusters involved in synthesis of secondary metabolites are identical in KKLW and FZB42, despite the fact that they were isolated from very different habitats, suggesting that the constitution of secondary metabolites among KKD1 and FZB42 was caused by the species differences, not the environmental factors.

It is known that the representatives of the B. amyloliquefaciens operational group [18] possess a higher diversity of secondary metabolites than other members of the B. subtilis species complex. In fact, the plant-associated B. velezensis FZB42 has devoted more than $10 \%$ of its genomic capacity to the synthesis of secondary metabolites with antimicrobial action [8]. Our AntiSMASH-supported analysis of the B. velezensis FZB42 and KKLW genome corroborated the occurrence of additional gene clusters not present in $B$. halotolerans KKD1 (Figure 9). In addition to bacillaene, the genomes of FZB42 and KKLW harbor two additional giant gene clusters devoted to the non-ribosomal synthesis of the type I trans-AT polyketides macrolactin and difficidin. Macrolactin and difficidin might be considered unique phylogenetic markers for the species B. velezensis [42]. Difficidin in particular is a powerful antibacterial metabolite [14]. Another gene cluster devoted to the non-ribosomal synthesis of the cyclic lipopeptide bacillomycin D, not occurring in KKD1, was detected in the genomes of FZB42 and KKLW. Bacillomycin D is known as the main antifungal acting metabolite in the plant-associated model strain FZB42 [8]. Gene clusters for the ribosomal synthesized bacteriocins (RiPPs) plantazolicin and amylocyclicin were detected in the genome of KKLW and FZB42, but not in the KKD1 genome [43].

A comparison of all gene clusters involved in the non-ribosomal and ribosomal synthesis of secondary metabolites with antimicrobial action detected by antiSMASH analysis of the KKD1, FZB42 and KKLW genomes is presented in Supplementary Table S5.

\subsection{Detection of Surfactin and Fengycin in the Supernatant of KKD1}

The lipopeptides present in the culture supernatant of several Bacillus species are known to inhibit plant pathogens. The B. halotolerans KKD1 strain developed antifungal activity against $F$. graminearum, as described in Section 3.6. The expression of surfactin and fengycin in KKD1 was experimentally validated by HPLC and MALDI-TOF-MS. We extracted the crude lipopeptides from strain KKD1 and analyzed the main components by HPLC and MALDI-TOF-MS. Two lipopeptide peaks were detected by HPLC (Figure 9). We purified the compounds obtained from these two peaks and analyzed their components by MALDI-TOF-MS. The molecular weight of the lipopeptides was estimated to be in the range of 900-2000 kDa (Figure 10A,B). The molecular masses of the ions at $m / z 1030.59$ corresponded to $\mathrm{C}_{13}$ surfactin $\mathrm{A}[\mathrm{M}+\mathrm{Na}]^{+}$, at $m / z 1074.60$ to $\mathrm{C}_{16}$ surfactin $\mathrm{A}[\mathrm{M}+\mathrm{Na}]^{+}$, at $m / z 1030.59$ to $C_{13}$ surfactin $\mathrm{A}[\mathrm{M}+\mathrm{Na}]^{+}$, at $m / z 1486.71$ to $\mathrm{C}_{16}$ fengycin $\mathrm{A}[\mathrm{M}+\mathrm{Na}]^{+}$, and at $m / z 1501.69$ to $\mathrm{C}_{14}$ fengycin $\mathrm{B}[\mathrm{M}+\mathrm{K}]^{+}$. 


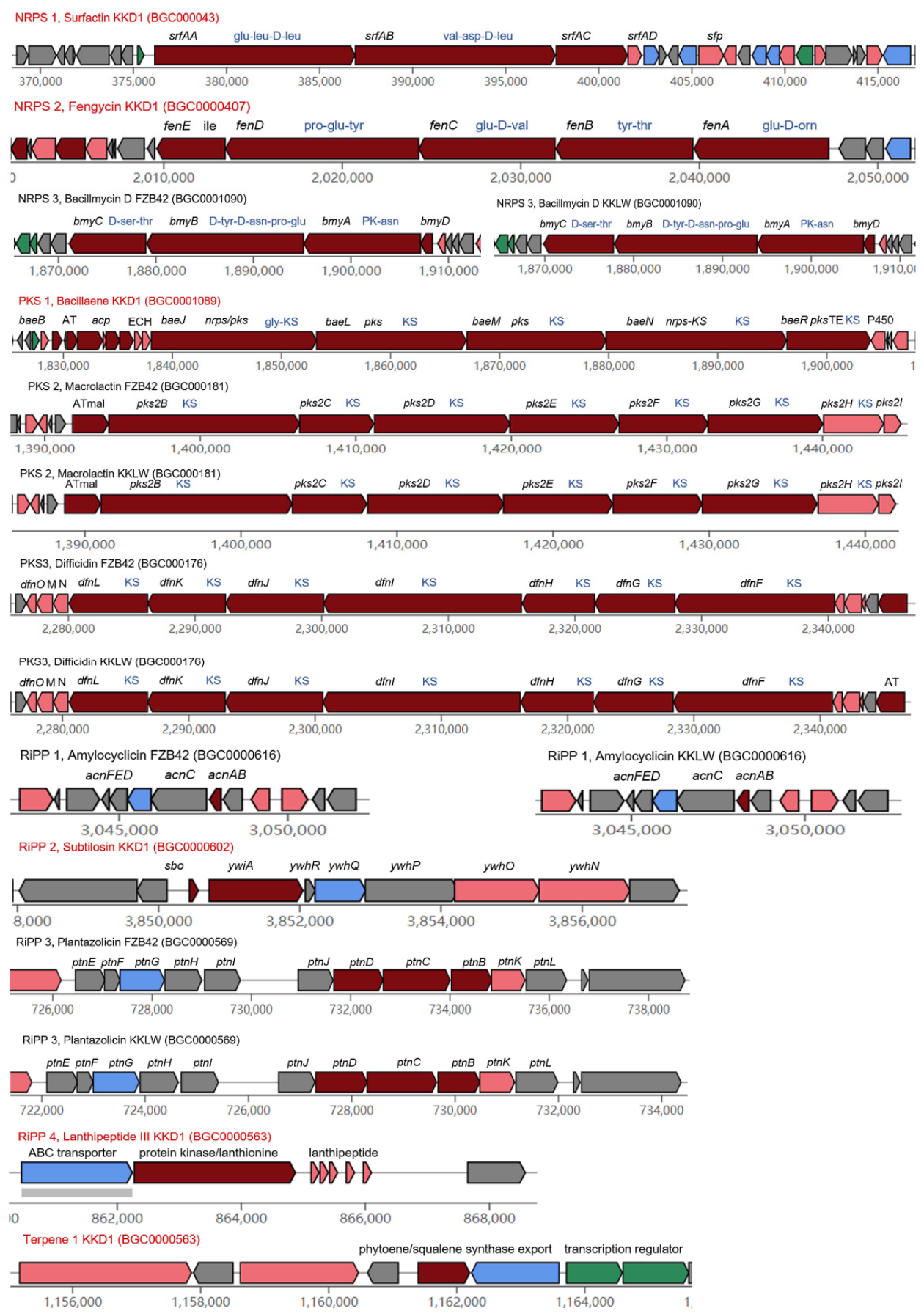

Figure 9. Thebiosynthetic gene clusters involved in the antagonistic activity of KKD1, FZB42 and KKLW. Detection of the gene clusters devoted to the synthesis of secondary metabolites was accomplished with antiSMASH 6.0. The genome of B. halotolerans KKD1 contains the gene clusters for the non-ribosomal synthesis of surfactin (NRPS), fengycin/plipastatin (NRPS), bacillibactin (NRPS), and bacilysin (other). Trans-AT-polyketide-synthases (PKS) type I accomplish the non-ribosomal synthesis of bacillaene. Chalcone/stilbene synthesis is accomplished by type III polyketide synthase (T3PKS). Additional gene clusters involved in the non-ribosomal synthesis of secondary metabolites are present in B. velezensis FZB42 and KKLW: bacillomycin D (NRPS), macrolactin (PKS), and difficidin (PKS). Ribosomal synthesis of peptides with antagonistic action against competing microorganisms occurs in KKD1, such as subtilosin, and uncharacterized lanthipeptide II. FZB42 and KKLW are characterized by ribosomal synthesis of RiPPs amylocyclicin and plantazolicin, which were previously described in B. velezensis FZB42. 

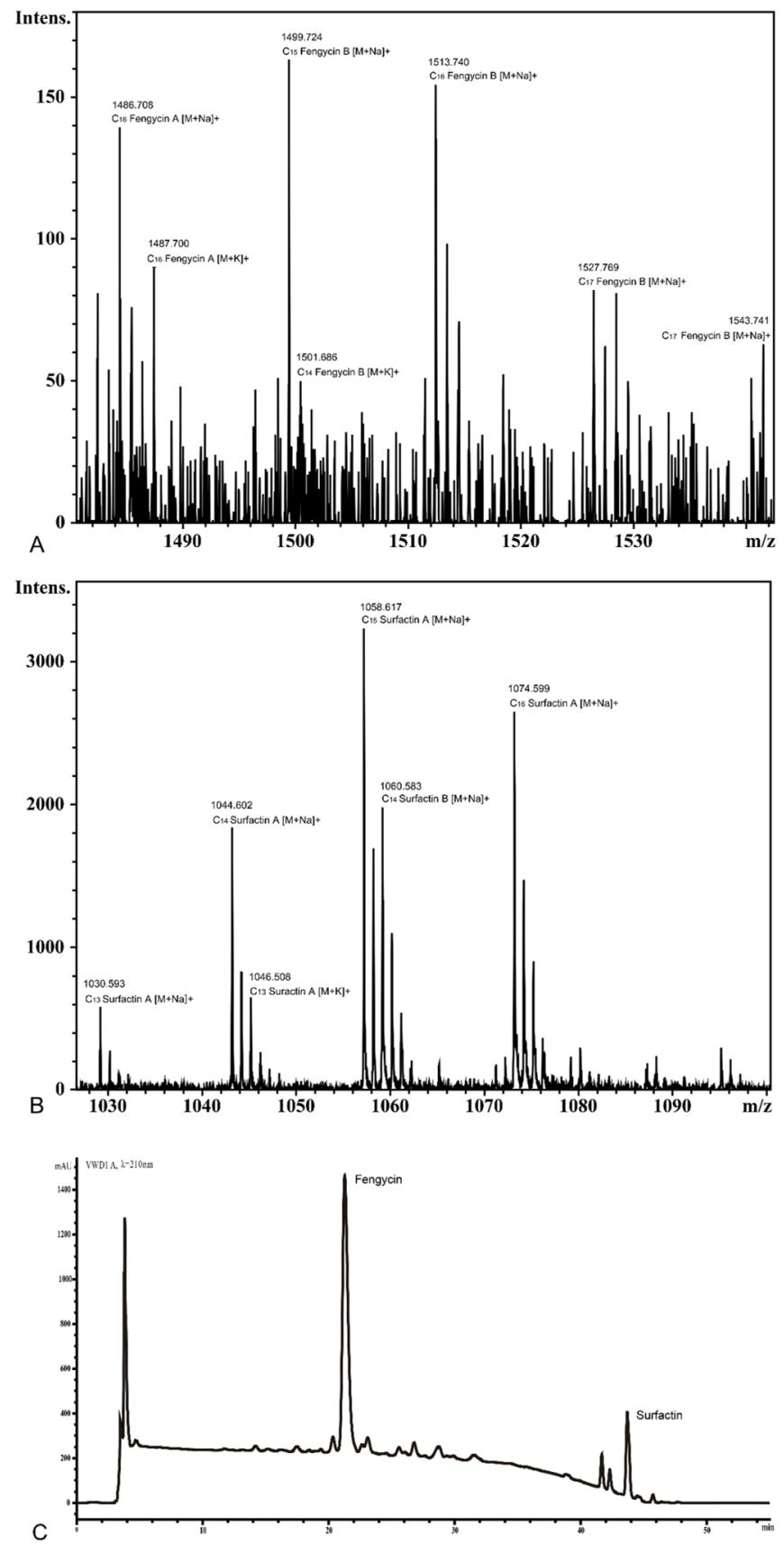

Figure 10. MALDI-TOF-MS and HPLC analysis of lipopeptide in B. halotolerans KKD1. (A) MALDITOF-MS analysis of surfactin in B. halotolerans KKD1. (B) MALDI-TOF-MS analysis of fengycin in B. halotolerans KKD1. (C) HPLC analysis of lipopeptide in B. halotolerans KKD1.

\section{Conclusions}

Using microorganisms from the QTP as biofertilizer is a suitable technique for developing of environmentally friendly biologicals that may be used in agriculture in harsh conditions. The extremophilic B. halotolerans KKD1 isolated from Hoh Xil possesses a strong biological potential to plant pathogens, and can propagate under high salinity and alkalinity stresses. B. halotolerans KKD1 contains four unique genes involved in different mechanisms of stress tolerance which not occurring in the model strains FZB42 and 168: sodium symporter family transporter (gene2258), and the sodium: dicarboxylate symporter (gene0525). Moreover, KKD1 also exhibits promising biocontrol activity against plant pathogens due to its production of surfactin, fengycin, and other secondary metabolites 
such as different bacteriocins. In conclusion, the result revealed that $B$. halotolerans KKD1 could be developed as a promising biological agent under harsh environmental conditions.

Supplementary Materials: The following are available online at https:/ /www.mdpi.com/article/10 .3390/biology10101030/s1, Figure S1: Genomic analysis based on COG database, Figure S2: Genomic analysis based on KEGG database, Figure S3: Genomic analysis based on GO database, Figure S4: The sRNAs and their target mRNA binding sites in B. halotolerans KKD1. Table S1: Isolation sites of the Bacillus strains collected from the QTP, Table S2: The RT-qPCR primers for detection of genes in this study, Table S3: The PCR primers for detection of genes in this study, Table S4: NCBI accession numbers of the gyrB and 16SrRNA partial sequences of the QTP isolates, Table S5: Biosynthetic gene clusters occurring in KKD1, FZB42 and KKLW.

Author Contributions: X.G., Y.X. and H.W. designed the study and administrated the project. X.W. and Y.X. isolated strains. X.W. performed the experiments, created bioinformatics tools, analyzed data, and wrote the draft version of the manuscript. R.W. performed part of RT-qPCR and pot experiments, analyzed the genome data. Y.Z. performed part of lipopeptides extraction and pot experiments. Z.W. analyzed the comparative genomic data. Q.G., X.W., R.W., Y.Z., R.B., A.F., M.S., X.Y. and Z.W. revised the manuscript with comments from all authors. The final version of the MS was prepared by R.B. All authors have read and agreed to the published version of the manuscript.

Funding: This work was funded by the regional innovation and development joint fund of National Natural Science Foundation of China [Grant NO: U20A2039], the International Sci-technology Cooperation Project of Qinghai Provincial Science and Technology Department [Grant NO: 2018-HZ-813], State Key Laboratory of Plateau Ecology and Agriculture (2019-ZZ-12), and National Natural Science Foundation of China [Grant NO: 31660543].

Institutional Review Board Statement: Not applicable.

Informed Consent Statement: Not applicable.

Data Availability Statement: Not applicable.

Acknowledgments: The authors are grateful to the authorities of the respective departments for support in doing this research. We also want to thank LetPub (www.letpub.com, accessed on 9 August 2021) for its linguistic assistance during the preparation of this manuscript.

Conflicts of Interest: The authors declare to have no competing interests.

\section{References}

1. Mipam, T.-D.; Zhong, L.-L.; Liu, J.-Q.; Miehe, G.; Tian, L.-M. Productive Overcompensation of Alpine Meadows in Response to Yak Grazing in the Eastern Qinghai-Tibet Plateau. Front. Plant Sci. 2019, 10, 925. [CrossRef]

2. Ren, Z.; Niu, D.; Ma, P.; Wang, Y.; Wang, Z.; Fu, H.; Elser, J.J. Bacterial Communities in Stream Biofilms in a Degrading Grassland Watershed on the Qinghai-Tibet Plateau. Front. Microbiol. 2020, 11, 1021. [CrossRef] [PubMed]

3. Wu, H.; Gu, Q.; Xie, Y.; Lou, Z.; Xue, P.; Fang, L.; Yu, C.; Jia, D.; Huang, G.; Zhu, B.; et al. Cold-adapted Bacilli isolated from the Qinghai-Tibetan Plateau are able to promote plant growth in extreme environments. Environ. Microbiol. 2019. [CrossRef]

4. Chu, T.N.; Bui, L.V.; Hoang, M.T.T. Pseudomonas PS01 Isolated from Maize Rhizosphere Alters Root System Architecture and Promotes Plant Growth. Microorganisms 2020, 8, 471. [CrossRef] [PubMed]

5. Ansari, S.H.; Ahmed, A.; Razzaq, A.; Hildebrandt, D.; Liu, X.; Park, Y.-K. Incorporation of solar-thermal energy into a gasification process to co-produce bio-fertilizer and power. Environ. Pollut. 2020, 266, 115103. [CrossRef]

6. Zubair, M.; Hanif, A.; Farzand, A.; Sheikh, T.M.M.; Khan, A.R.; Suleman, M.; Ayaz, M.; Gao, X. Genetic Screening and Expression Analysis of Psychrophilic Bacillus spp. Reveal Their Potential to Alleviate Cold Stress and Modulate Phytohormones in Wheat. Microorganisms 2019, 7, 337. [CrossRef] [PubMed]

7. Azmat, A.; Yasmin, H.; Hassan, M.N.; Nosheen, A.; Naz, R.; Sajjad, M.; Ilyas, N.; Akhtar, M.N. Co-application of bio-fertilizer and salicylic acid improves growth, photosynthetic pigments and stress tolerance in wheat under drought stress. PeerJ 2020, 8, e9960. [CrossRef]

8. Chen, X.H.; Koumoutsi, A.; Scholz, R.; Eisenreich, A.; Schneider, K.; Heinemeyer, I.; Morgenstern, B.; Voss, B.; Hess, W.R.; Reva, O.; et al. Comparative analysis of the complete genome sequence of the plant growth-promoting bacterium Bacillus amyloliquefaciens FZB42. Nat. Biotechnol. 2007, 25, 1007-1014. [CrossRef]

9. Luo, C.; Chen, Y.; Liu, X.; Wang, X.; Wang, X.; Li, X.; Zhao, Y.; Wei, L. Engineered biosynthesis of cyclic lipopeptide locillomycins in surrogate host Bacillus velezensis FZB42 and derivative strains enhance antibacterial activity. Appl. Microbiol. Biotechnol. 2019, 103, 4467-4481. [CrossRef] 
10. Massawe, V.C.; Hanif, A.; Farzand, A.; Mburu, D.K.; Ochola, S.O.; Wu, L.; Tahir, H.A.S.; Gu, Q.; Wu, H.; Gao, X. Volatile Compounds of Endophytic Bacillus spp. have Biocontrol Activity against Sclerotinia sclerotiorum. Phytopathology 2018, 108, 1373-1385. [CrossRef]

11. Kumar, S.; Stecher, G.; Tamura, K. MEGA7: Molecular Evolutionary Genetics Analysis Version 7.0 for Bigger Datasets. Mol. Biol. Evol. 2016, 33, 1870-1874. [CrossRef]

12. Hanif, A.; Zhang, F.; Li, P.; Li, C.; Xu, Y.; Zubair, M.; Zhang, M.; Jia, D.; Zhao, X.; Liang, J.; et al. Fengycin Produced by Bacillus amyloliquefaciens FZB42 Inhibits Fusarium graminearum Growth and Mycotoxins Biosynthesis. Toxins 2019, 11, 295. [CrossRef]

13. Gu, Q.; Tahir, H.A.S.; Zhang, H.; Huang, H.; Ji, T.; Sun, X.; Wu, L.; Wu, H.; Gao, X. Involvement of FvSet1 in Fumonisin B1 Biosynthesis, Vegetative Growth, Fungal Virulence, and Environmental Stress Responses in Fusarium verticillioides. Toxins 2017, 9, 43. [CrossRef] [PubMed]

14. Wu, L.; Wu, H.; Chen, L.; Yu, X.; Borriss, R.; Gao, X. Difficidin and bacilysin from Bacillus amyloliquefaciens FZB42 have antibacterial activity against Xanthomonas oryzae rice pathogens. Sci. Rep. 2015, 5, 12975. [CrossRef] [PubMed]

15. Reeve, M.A.; Bachmann, D. MALDI-TOF MS protein fingerprinting of mixed samples. Biol. Methods Protoc. 2019,4 , bpz013. [CrossRef] [PubMed]

16. Farzand, A.; Moosa, A.; Zubair, M.; Khan, A.R.; Massawe, V.C.; Tahir, H.A.S.; Sheikh, T.M.M.; Ayaz, M.; Gao, X. Suppression of Sclerotinia sclerotiorum by the Induction of Systemic Resistance and Regulation of Antioxidant Pathways in Tomato Using Fengycin Produced by Bacillus amyloliquefaciens FZB42. Biomolecules 2019, 9, 613. [CrossRef]

17. Aliyu, H.; Lebre, P.; Blom, J.; Cowan, D.; De Maayer, P. Phylogenomic re-assessment of the thermophilic genus Geobacillus. Syst. Appl. Microbiol. 2016, 39, 527-533. [CrossRef]

18. Fan, B.; Blom, J.; Klenk, H.-P.; Borriss, R. Bacillus amyloliquefaciens, Bacillus velezensis, and Bacillus siamensis Form an "Operational Group B. amyloliquefaciens" within the B. subtilis Species Complex. Front. Microbiol. 2017, 8, 22. [CrossRef]

19. Fritze, D. Taxonomy of the genus bacillus and related genera: The aerobic endospore-forming bacteria. Phytopathology 2004, 94 , 1245-1248. [CrossRef]

20. Goris, J.; Konstantinidis, K.T.; Klappenbach, J.A.; Coenye, T.; Vandamme, P.; Tiedje, J.M. DNA-DNA hybridization values and their relationship to whole-genome sequence similarities. Int. J. Syst. Evol. Microbiol. 2007, 57, 81-91. [CrossRef]

21. Ara, K.; Ozaki, K.; Nakamura, K.; Yamane, K.; Sekiguchi, J.; Ogasawara, N. Bacillus minimum genome factory: Effective utilization of microbial genome information. Biotechnol. Appl. Biochem. 2007, 46, 169-178. [CrossRef] [PubMed]

22. Hoffmann, T.; von Blohn, C.; Stanek, A.; Moses, S.; Barzantny, H.; Bremer, E. Synthesis, release, and recapture of compatible solute proline by osmotically stressed Bacillus subtilis cells. Appl. Environ. Microbiol. 2012, 78, 5753-5762. [CrossRef] [PubMed]

23. Hoffmann, T.; Bleisteiner, M.; Sappa, P.K.; Steil, L.; Mäder, U.; Völker, U.; Bremer, E. Synthesis of the compatible solute proline by Bacillus subtilis: Point mutations rendering the osmotically controlled proHJ promoter hyperactive. Environ. Microbiol. 2017, 19, 3700-3720. [CrossRef]

24. El-Esawi, M.A.; Alaraidh, I.A.; Alsahli, A.A.; Alamri, S.A.; Ali, H.M.; Alayafi, A.A. Bacillus firmus (SW5) augments salt tolerance in soybean (Glycine max L.) by modulating root system architecture, antioxidant defense systems and stress-responsive genes expression. Plant Physiol. Biochem. PPB 2018, 132, 375-384. [CrossRef]

25. Bürklen, L.; Schöck, F.; Dahl, M.K. Molecular analysis of the interaction between the Bacillus subtilis trehalose repressor TreR and the tre operator. Mol. Gen. Genet. 1998, 260, 48-55. [CrossRef]

26. Servet, C.; Ghelis, T.; Richard, L.; Zilberstein, A.; Savoure, A. Proline dehydrogenase: A key enzyme in controlling cellular homeostasis. Front. Biosci. (Landmark Ed.) 2012, 17, 607-620. [CrossRef]

27. Laye, V.J.; DasSarma, S. An Antarctic Extreme Halophile and Its Polyextremophilic Enzyme: Effects of Perchlorate Salts. Astrobiology 2018, 18, 412-418. [CrossRef] [PubMed]

28. Kitada, M.; Kosono, S.; Kudo, T. The Na+/H+ antiporter of alkaliphilic Bacillus sp. Extremophiles 2000, 4, 253-258. [CrossRef] [PubMed]

29. Crowe-McAuliffe, C.; Graf, M.; Huter, P.; Takada, H.; Abdelshahid, M.; Nováček, J.; Murina, V.; Atkinson, G.C.; Hauryliuk, V.; Wilson, D.N. Structural basis for antibiotic resistance mediated by the Bacillus subtilis ABCF ATPase VmlR. Proc. Natl. Acad. Sci. USA 2018, 115, 8978-8983. [CrossRef]

30. Cheng, B.; Meng, Y.; Cui, Y.; Li, C.; Tao, F.; Yin, H.; Yang, C.; Xu, P. Alkaline Response of a Halotolerant Alkaliphilic Halomonas Strain and Functional Diversity of Its $\mathrm{Na}^{+}\left(\mathrm{K}^{+}\right) / \mathrm{H}^{+}$Antiporters. J. Biol. Chem. 2016, 291, 26056-26065. [CrossRef]

31. Mirouze, N.; Ferret, C.; Cornilleau, C.; Carballido-López, R. Antibiotic sensitivity reveals that wall teichoic acids mediate DNA binding during competence in Bacillus subtilis. Nat. Commun. 2018, 9, 5072. [CrossRef] [PubMed]

32. Kunst, F.; Ogasawara, N.; Moszer, I.; Albertini, A.M.; Alloni, G.; Azevedo, V.; Bertero, M.G.; Bessières, P.; Bolotin, A.; Borchert, S.; et al. The complete genome sequence of the gram-positive bacterium Bacillus subtilis. Nature 1997, 390, 249-256. [CrossRef] [PubMed]

33. Blin, K.; Shaw, S.; Steinke, K.; Villebro, R.; Ziemert, N.; Lee, S.Y.; Medema, M.H.; Weber, T. antiSMASH 5.0: Updates to the secondary metabolite genome mining pipeline. Nucleic Acids Res. 2019, 47, W81-W87. [CrossRef] [PubMed]

34. Weber, T.; Blin, K.; Duddela, S.; Krug, D.; Kim, H.U.; Bruccoleri, R.; Lee, S.Y.; Fischbach, M.A.; Müller, R.; Wohlleben, W.; et al. antiSMASH 3.0-A comprehensive resource for the genome mining of biosynthetic gene clusters. Nucleic Acids Res. 2015, 43, W237-W243. [CrossRef] 
35. Keswani, C.; Singh, H.B.; Hermosa, R.; García-Estrada, C.; Caradus, J.; He, Y.-W.; Mezaache-Aichour, S.; Glare, T.R.; Borriss, R.; Vinale, F.; et al. Antimicrobial secondary metabolites from agriculturally important fungi as next biocontrol agents. Appl. Microbiol. Biotechnol. 2019, 103, 9287-9303. [CrossRef]

36. Ali, S.; Hameed, S.; Shahid, M.; Iqbal, M.; Lazarovits, G.; Imran, A. Functional characterization of potential PGPR exhibiting broad-spectrum antifungal activity. Microbiol. Res. 2020, 232, 126389. [CrossRef]

37. Zhao, H.; Shao, D.; Jiang, C.; Shi, J.; Li, Q.; Huang, Q.; Rajoka, M.S.R.; Yang, H.; Jin, M. Biological activity of lipopeptides from Bacillus. Appl. Microbiol. Biotechnol. 2017, 101, 5951-5960. [CrossRef] [PubMed]

38. Kumar, A.; Singh, S.; Mukherjee, A.; Rastogi, R.P.; Verma, J.P. Salt-tolerant plant growth-promoting Bacillus pumilus strain JPVS11 to enhance plant growth attributes of rice and improve soil health under salinity stress. Microbiol. Res. 2021, 242, 126616. [CrossRef]

39. Moldenhauer, J.; Götz, D.C.G.; Albert, C.R.; Bischof, S.K.; Schneider, K.; Süssmuth, R.D.; Engeser, M.; Gross, H.; Bringmann, G.; Piel, J. The final steps of bacillaene biosynthesis in Bacillus amyloliquefaciens FZB42: Direct evidence for beta, gamma dehydration by a trans-acyltransferase polyketide synthase. Angew. Chem. Int. Ed. Engl. 2010, 49, 1465-1467. [CrossRef]

40. Chatterjee, C.; Paul, M.; Xie, L.; van der Donk, W.A. Biosynthesis and mode of action of lantibiotics. Chem. Rev. 2005, 105, 633-684. [CrossRef]

41. Putkaradze, N.; Litzenburger, M.; Abdulmughni, A.; Milhim, M.; Brill, E.; Hannemann, F.; Bernhardt, R. CYP109E1 is a novel versatile statin and terpene oxidase from Bacillus megaterium. Appl. Microbiol. Biotechnol. 2017, 101, 8379-8393. [CrossRef] [PubMed]

42. Schneider, K.; Chen, X.-H.; Vater, J.; Franke, P.; Nicholson, G.; Borriss, R.; Süssmuth, R.D. Macrolactin is the polyketide biosynthesis product of the pks2 cluster of Bacillus amyloliquefaciens FZB42. J. Nat. Prod. 2007, 70, 1417-1423. [CrossRef] [PubMed]

43. Scholz, R.; Molohon, K.J.; Nachtigall, J.; Vater, J.; Markley, A.L.; Süssmuth, R.D.; Mitchell, D.A.; Borriss, R. Plantazolicin, a novel microcin B17/streptolysin S-like natural product from Bacillus amyloliquefaciens FZB42. J. Bacteriol. 2011, 193, 215-224. [CrossRef] [PubMed] 